\title{
Using oxygen and sulfur isotopes to partition sources of riverine sulfate
}

\author{
K. E. ReLPH ${ }^{1 *}$, E. I. STEVENSON ${ }^{2}$, A.V. TURCHYN ${ }^{1}$, \\ G. ANTLER ${ }^{2}$, M. J. BICKLE ${ }^{1}$, J. J. BARONAS ${ }^{1}$, \\ D. R. PARSONS ${ }^{3}$, S.E. DARBY ${ }^{4}$, E. T. TIPPER ${ }^{1}$ \\ ${ }^{1}$ Department of Earth Sciences, University of Cambridge, \\ Cambridge, CB2 3EQ, UK *ker42@cam.ac.uk \\ ${ }^{2}$ Department of Geological and Environmental Sciences, \\ Ben-Gurion University of the Negev, Israel \\ ${ }^{3}$ Energy and Environment Institute, University of Hull, Hull, \\ HU6 7RX, UK \\ ${ }^{4}$ Geography and Environment, University of Southampton, \\ Southampton, SO17 1BJ, UK
}

Sulfuric acid weathering of carbonate rocks releases $\mathrm{CO}_{2}$ to the atmosphere offsetting the $\mathrm{CO}_{2}$ drawdown from carbonic acid weathering of silicates thought to regulate global climate. Quantifying sulfuric acid weathering requires the source of riverine sulfate to be determined. Sulfate comes from predominantly two sources: sedimentary sulfate (which does not affect the carbon cycle) and oxidative weathering of sulfides (which produces sulfuric acid, releasing 1 mole of $\mathrm{CO}_{2}$ for each mole of carbonate weathered). Here we present a new two endmember mixing model to partition the fraction of dissolved sulfate derived from the oxidative weathering of pyrite $\left(f_{\mathrm{pyr}}\right)$ and show that a local pyrite endmember can be characterised with $\delta^{18} \mathrm{O}$ of local water. Partitioning sulfate sources is demonstrated in one of the world's largest river basins using new $\delta^{18} \mathrm{O}_{\mathrm{SO} 4}, \delta^{18} \mathrm{O}_{\mathrm{H} 2 \mathrm{O}}$ and $\delta^{34} \mathrm{~S}_{\mathrm{SO} 4}$ data collected on 18 tributaries and 5 mainstem sites of the Mekong river. In the Mekong tributaries sources of sulfate are highly variable with $f_{\mathrm{pyr}}$ ranging from 0.17 to $0.89 .49 \%$ of the sulfate delivered to the ocean at the Mekong mouth is derived from oxidative weathering of pyrite, calculated by summing upstream and tributary inputs. Our carbon budget of this mega river determines that $\mathrm{CO}_{2}$ is released to the atmosphere over long term timescales, highlighting the importance of precisely determining the origin of sulfate in the world's largest rivers for the global carbon cycle. 